\title{
Study on the flexural performance of RC beams anchored with CFRP plates under secondary load
}

\author{
Xiangrui Feng, Xian Cui*, Haikun Luo \\ Departments of Structural Engineering, Yanbian University, Yanji, Jilin, 133002, China
}

\begin{abstract}
In order to explore the influence of length and width of CFRP as well as anchor spacing on the reinforcement effectiveness of CFRP plates on reinforcement concrete beams (RC beams) under secondary load, 7 anchored damaged FRP reinforced concrete beams are used as test beams, 1 unanchored beam is used as a control beam, and structural indicators such as ultimate load and bending strength are analyzed in the result. The conclusion is that composite CFRP plate can effectively prevent the early peeling and failure of carbon plates and improve the ultimate bearing capacity of the beam. When the width of the CFRP plate decreases, the thickness increases and the steel plate anchor spacing increases appropriately, the ultimate bearing capacity and ductility of the beam are significantly improved.
\end{abstract}

\section{Introduction}

With the rapid economic development, China's current construction industry is in a period during which both construction and maintenance are equally emphasized. One of the important characteristics of this period is that old buildings, which were constructed with low standards and fell into disrepair because of natural environment and long-term usage, can no longer meet the needs of modern society, and urgently require repair and reinforcement ${ }^{[1]}$.

Carbon fiber is a new reinforced polymer and has the advantages of being lightweight, strong, corrosionresistant, easy to use and high cost effective ${ }^{[2]}$. It has been widely studied and applied in academia and engineering fields. Shang Shouping ${ }^{[3]}$ et al. studied the properties of different carbon fiber cloth materials and found that prestressed carbon fiber cloth materials can greatly improve the working performance of the beam. Gao Danying ${ }^{[4]}$ studied the influence of span-to-height ratio, longitudinal reinforcement ratio and CFRP layer number on reinforced concrete beams, and found that when the span-to-height ratio decreases and the longitudinal reinforcement ratio and the number of layers increase, the ultimate bearing capacity of the beam has been significantly improved. Gao also proposed the calculation method of short beam. Zhao Ming ${ }^{[5]}$ et al. studied the influence of factors such as the ratio of tensile longitudinal reinforcement and concrete strength on the performance of beam structures, and found that concrete flexural members reinforced with externally bonded carbon fiber sheets can effectively increase the section bearing capacity, restrain cracks and improve its rigidity.

However, most of the current researches focus on undamaged concrete beams reinforced with CFRP, and seldom focuses on damaged concrete beams, which forms a gap with current actual production and application ${ }^{[6]}$.

In the test, 8 reinforced concrete beams are used, among which 1 beam is used as a control beam, and the other 7 beams are used as test beams. The control beam is loaded with static load until failure happens. The 7 test beams are loaded with $40 \%$ of the maximum static load and then unloaded, then CFRP plates of different lengths, thicknesses and anchor spacing are glued on the beam and flexual tests are carried out again until failure happens. Compare their mechanical performances and obtain the optimal reinforcement method. It is hoped that this paper can provide a test reference for actual engineering reinforcement practice.

\section{Test}

\subsection{Making of beams}

The concrete design strength grade of the experimental beams is C30, and the mix ratio is cement: sand: stone: water $=1: 2.15: 2.32: 0.44$. The compressive strength of the cubic standard test block is $37.8 \mathrm{Mpa}, \mathrm{Ec}=4.8 \times 104 \mathrm{MPa}$. All test beams are simply supported beams with rectangular cross-section, the cross-section size $\mathrm{b} \times \mathrm{h}=150 \mathrm{~mm} \times 200 \mathrm{~mm}$, the total length $\mathrm{l}=1400 \mathrm{~mm}$, the clear span $10=1200 \mathrm{~mm}$, the longitudinal tensile steel bars and the erecting bars is $2 \varphi 16$, and the reinforcement ratio is $1.34 \%$. The stirrup is $\varphi 8 @ 100$, as shown in Figure 1. The standard strength of CFRP plate is $250 \mathrm{MPa}$, and the elastic modulus is $160 \mathrm{GPa}$. The anchor is composed of a steel sheet, two screws, two nuts and two washers of the same size, and the thickness of the anchored steel plate is $4 \mathrm{~mm}$. The detailed dimensions are shown in Figure 2.

\footnotetext{
*Corresponding author's E-mail: cxian@ybu.edu.cn
} 
The detailed design parameters of the beam are shown in Table 1.

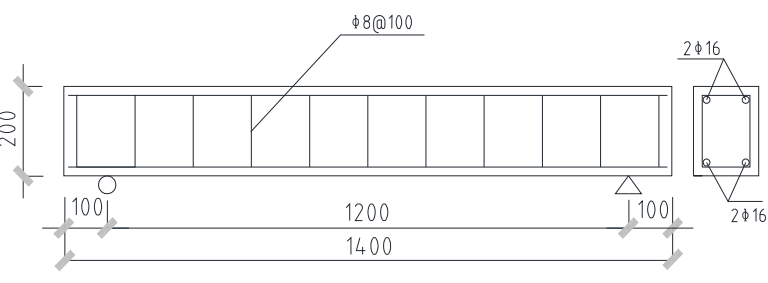

Fig. 1. detailed dimension and reinforcement diagram of test piece

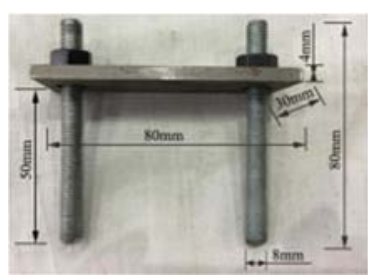

Fig 2 anchors

Table 1. Parameters of test beams

\begin{tabular}{ccccc}
\hline No. & $\begin{array}{c}\text { Damage } \\
\text { degree }\end{array}$ & $\begin{array}{c}\text { Thickness } \\
\text { of CFRP } \\
\text { panels } \\
(\mathrm{mm})\end{array}$ & $\begin{array}{c}\text { Width } \\
\text { of } \\
\text { CFRP } \\
(\mathrm{mm})\end{array}$ & $\begin{array}{c}\text { Anchor } \\
\text { spacing } \\
(\mathrm{mm})\end{array}$ \\
\hline L0 & $40 \%$ & 1.0 & 60 & Unanchored \\
\hline L1 & $40 \%$ & 1.0 & 40 & 200 \\
\hline L2 & $40 \%$ & 1.0 & 50 & 200 \\
\hline L3 & $40 \%$ & 1.0 & 60 & 150 \\
\hline L4 & $40 \%$ & 0.8 & 60 & 200 \\
\hline L5 & $40 \%$ & 1.0 & 60 & 200 \\
\hline L6 & $40 \%$ & 1.2 & 60 & 200 \\
\hline L7 & $40 \%$ & 1.0 & 60 & 250 \\
\hline
\end{tabular}

\subsection{Anchoring method}

Based on domestic and foreign researches on the reinforcement of concrete with CFRP plates ${ }^{[7]-[12]}$, a composite reinforcement method proposed by Cheng Ye is used in this test, that is using steel plates and FRP to reinforce the beams. Combining the characteristics of this test, the final reinforcement method is as follows: (1) Determine drilling positions according to pre-determined anchor spacing and anchorage length, use an electric drill to drill holes with a diameter of $8 \mathrm{~mm}$ and a depth of about $40 \mathrm{~mm}$, and use alcohol cotton to seal the holes after dust removal treatment. (2) Use a glue gun to inject an appropriate amount of anchoring glue into the holes, rotate screws into the holes, and tune the position of the screws to keep them vertical before the glue solidifies. (3) Apply a layer of $1 \mathrm{~mm}$ thick adhesive glue to the position where the CFRP plate is pasted, clean the CFRP plates with alcohol and paste them to the bottom of the beam. (4) Maintain the position of CFRP plates and anchor them to the bottom of the beams with anchors.

\subsection{Loading method}

In the RC beam flexural test, the beam is fixed at both ends, and static load is loaded in the middle of the beam. PWS-500 electro-hydraulic servo fatigue testing machine is used as loading device, as shown in Figure 3. During the test, steel plates are added to the position where stess is loaded, in order to prevent concrete from being crushed by the combined effect of the support and loading points. Pre-loading is conducted before formal test to check whether the support is stable, whether the instrument and loading device work normal, and find zero point. Formal loading is implemented after pre-loading. Step static loading mode is applied in the test, and the loading level is $2 \mathrm{KN} / \mathrm{s}$. When the bearing capacity drops to $85 \%$ of the peak bearing capacity or the beam is deformed so much that it cannot continue to bear the load, it will be regarded as failure and the load shall be stopped. A static loading test is conducted on the control beam to determine the yield load and ultimate load of the beams, which are 90 $\mathrm{KN}$ and $122 \mathrm{KN}$ respectively. The 7 test beams are loaded with $40 \%$ of the ultimate load to simulate the state of "damage", and the static load is then unloaded. Reinforce these beams with CFRP and conduct a second load test.

In order to study the stress condition of the test beams, strain gauges are set every $80 \mathrm{~mm}$ on the side of the steel bar in the tension zone of the beam, and DH2817 dynamic and static strain test system is used for data collection. The mid-span deflection and load of the test beams are collected by an actuator built-in sensor, which is also used for collecting and recording the test process such as the development of beam cracks in real time.

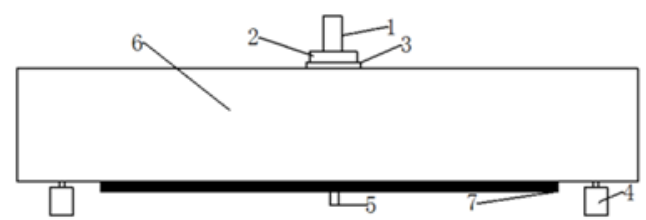

1. Reaction beam 2. Jack 3. Solid steel pipe 4. Support 5. Displacement meter 6. Test beams 7. Carbon plate

Fig. 3. Beam loading diagram

\section{Results and analysis}

\subsection{Damage form and cracks}

The yield load, ultimate load, yield displacement, ultimate displacement and failure mode of the test beams are shown in Table 2.

L0 is an unanchored FRP reinforced concrete beam. In the limit state, the carbon plate peels off and stops work without breaking. L1 L7 are reinforced beams with CFRP plates, but CFRP plates are not anchored. A loading force of $48 \mathrm{KN}$ is applied on the reinforced beams and then the CFRP plates are removed. All cracks are closed after unloading. When loading, the cracks in the reinforced beams develop similar patterns. At the initial stage of loading, a small crack appeared in the middle of the beam. As loading force increases, the crack becomes wider and new micro cracks appear diagonally near the loading 
points. As loading force continues to increase, the expanding speed of cracks to the top of the reinforced beams slows down, and the total number of cracks is significantly less than that of the control beam. When the failure finally occurs, CFRP plates split and break down but to different degree, accompanied by the sound of glue cracking. In the whole process, the carbon fiber board used for reinforcing secondary damaged RC beams did not peel off at the initial loading stage and the cracking stage, indicating that this anchoring method has a higher utilization rate of CFRP material and is more suitable for this type of reinforced concrete beam.

Table 2. Test results

\begin{tabular}{|c|c|c|c|c|c|c|c|}
\hline \multirow{2}{*}{ No. } & \multicolumn{3}{|c|}{ Yield state } & \multicolumn{3}{|c|}{ Ultimate state } & \multirow{2}{*}{ Damage mode } \\
\hline & $\begin{array}{l}\text { Loading force } \\
(\mathrm{KN})\end{array}$ & $\begin{array}{c}\text { Increase rate } \\
(\%)\end{array}$ & $\begin{array}{c}\text { Deflection } \\
(\mathrm{mm})\end{array}$ & $\begin{array}{l}\text { Loading force } \\
(\mathrm{KN})\end{array}$ & $\begin{array}{c}\text { Increase rate } \\
(\%)\end{array}$ & $\begin{array}{c}\text { Deflection } \\
(\mathrm{mm})\end{array}$ & \\
\hline L0 & 90 & - & 11 & 122 & - & 14 & $\begin{array}{c}\text { Carbon plate } \\
\text { peeling off }\end{array}$ \\
\hline $\mathrm{L} 1$ & 142 & 58 & 19 & 152 & 25 & 31 & $\begin{array}{c}\text { Carbon plate } \\
\text { cracking }\end{array}$ \\
\hline $\mathrm{L} 2$ & 106 & 18 & 12 & 167 & 37 & 20 & $\begin{array}{c}\text { Carbon plate } \\
\text { cracking }\end{array}$ \\
\hline L3 & 82 & -9 & 12 & 150 & 23 & 39 & $\begin{array}{l}\text { Carbon plate } \\
\text { cracking }\end{array}$ \\
\hline L4 & 104 & 16 & 12 & 168 & 38 & 20 & $\begin{array}{c}\text { Carbon plate } \\
\text { cracking }\end{array}$ \\
\hline L5 & 88 & -2 & 11 & 133 & 9 & 14 & $\begin{array}{l}\text { Carbon plate } \\
\text { cracking }\end{array}$ \\
\hline L6 & 102 & 13 & 14 & 165 & 35 & 20 & $\begin{array}{l}\text { Carbon plate } \\
\text { cracking }\end{array}$ \\
\hline L7 & 74 & -18 & 8 & 162 & 33 & 26 & $\begin{array}{l}\text { Carbon plate } \\
\text { cracking }\end{array}$ \\
\hline
\end{tabular}

\subsection{Load-strain curve analysis}

Figures $4 \sim 6$ show the load-strain curves of reinforced RC beams. Combining test data and test phenomena, it is concluded that:

For all secondary-damaged RC beams, in the initial stage, when the beam cracks and the steel bar yields, the value of the strain gauge increases linearly with the increase of loading force, and the strain capacity of all secondary-damaged beams is significantly improved. At the end stage of loading, due to the yield of the steel bar, the CFRP plate bears most of the stress, causing its strain to increase at a great rate until it fails.

Figure 4 shows the load-strain curve of reinforced beams with CFRP plates of different widths. It can be seen that the strain of three of the beams increases linearly at a similar rate during the initial loading stage and the cracking stage. When the loading force is close to $120 \mathrm{KN}$, the strain of L5 (with a CFRP of $60 \mathrm{~mm}$ ) increases rapidly. This is mainly because that CFRP plate is too wide and has a large contact surface with anchors, plates are not solidly glued to the beams since air is not exhausted out completely. Fiber breaks and fails after yielding.

Figure 5 shows the load-strain curves of reinforced beams with CFRP plates of different anchor spacings. At the initial loading stage, when the anchoring spacing reaches $250 \mathrm{~mm}$, the strain of $\mathrm{L} 7$ fluctuates greatly, showing extremely uneven trend. It suggests that when anchor spacing is large, the effective stress of the CFRP board should be considered.
Figure 6 shows the load-strain curve of reinforced beams with CFRP plates of different thickness. It can be seen that appropriately reducing the plate thickness can reduce the strain of the concrete beam. When loading force reaches $130 \mathrm{KN}$, the strain of the L4 beam (with a width of $0.8 \mathrm{~mm}$ ) is only $50 \%$ of the strain of L5 (with a width of $1.0 \mathrm{~mm}$ ). The CFRP plate of L5 beam peels off and fails, which affects the ultimate bearing capacity of the beam.

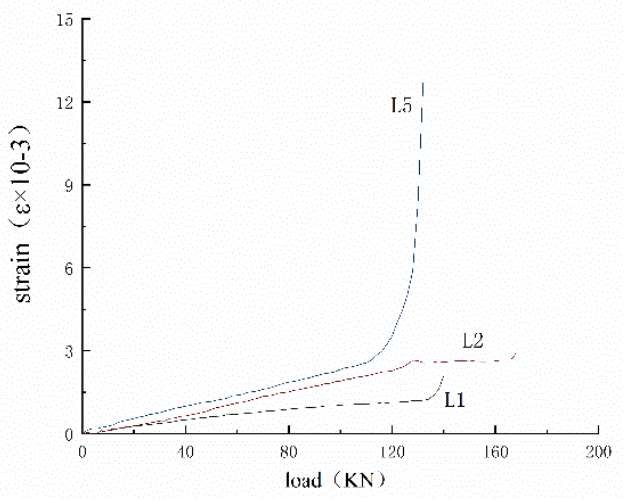

Fig. 4. Load-strain curves of RC beams with CFRP plate of different widths 


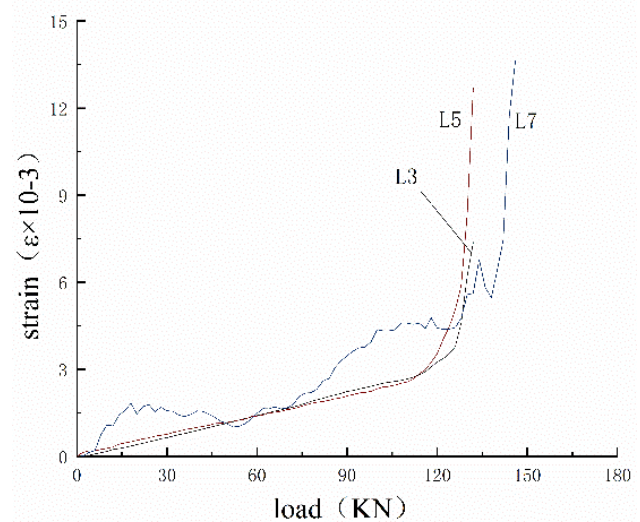

Fig. 5. Load-strain curves of RC beams with different anchoring space

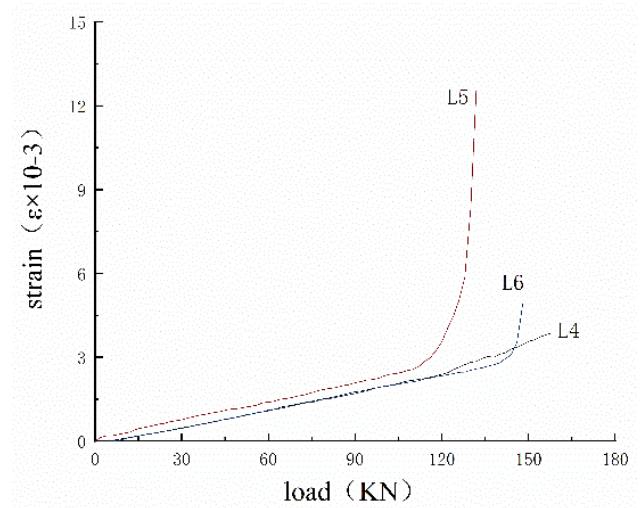

Fig. 6. Load-strain curves of RC beams with CFRP plate of different thickness

\subsection{Load-deflection curve analysis}

Figures 7 10 show the load-deflection curves of reinforced RC beams. Combining test data and test phenomena, it is concluded that:

For all secondary-damage beams, there is no significant difference in their deflection at the beginning of loading. Since loading force is increased gradually, all beams maintain good elasticity. Except for L3, the ultimate load of all reinforced beams has reached about $150 \mathrm{KN}$.

Figure 7 shows that the maximum deflection of the $\mathrm{RC}$ beam with a width of $40 \mathrm{~mm}$ CFRP plate is significantly greater than that of the other two beams. This is because there is smaller contact surface between carbon fiber plate and concrete beam when the carbon fiber plate is narrower, and smaller structure glue pores also increase deflection, which embodies the excellent tensile performance of carbon fiber plates.

Figure 8 shows that anchor spacing has significant impact on the ultimate bearing capacity of the beams. When anchor spacing is $150 \mathrm{~mm}$, the ultimate load of L3 beam is about $30 \%$ lower than that of the other two beams, which is not conducive to the use of the beams.

Figure 9 shows that the deflection of the beams reinforced with CFRP plate of $0.8 \mathrm{~mm}$ declines linearly after ultimate load is reached, and the maximum deflection of the beam is reduced by more than $35 \%$ compared with L6, which harms the ductility of the beam at a certain level.

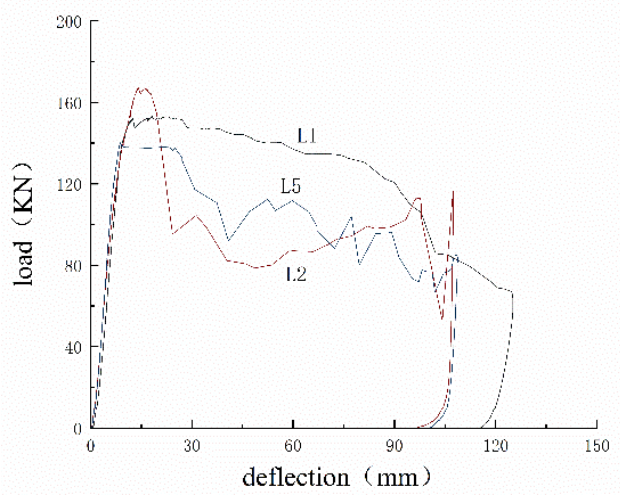

Fig. 7. Load-deflection curves of RC beams with CFRP plate of different widths

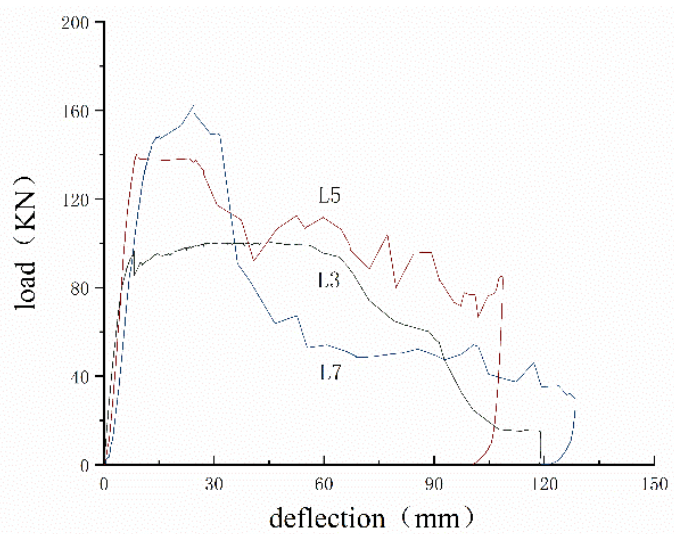

Fig. 8. Load-deflection curves of RC beams with different anchoring space

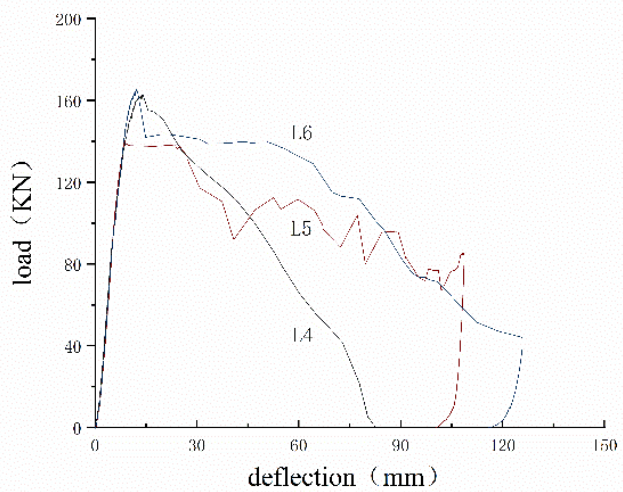

Fig. 9. Load-deflection curves of RC beams with CFRP plate of different thickness

\section{Conclusion}

(1) Comparing the method of pasting carbon plates with anchoring method, CFRP anchoring technology can obviously ameliorate the problem of carbon plate peeling off and improve the utilization rate of CFRP plates.

(2) The strengthening effect of CFRP plate on the flexural bearing capacity of concrete is mainly reflected after steel bar yields. The problems of deflection increase and stiffness degradation in the middle of the test beams are ameliorated obviously. When ultimate load is reached, the mid-span deflection increases slightly, which significantly improves the ductility of reinforced concrete.

(3) To a certain extent, as the width of the CFRP 
plate increases, the ultimate bearing capacity of the beam increases, but it is easy to peel off when the CFR plate is too wide, thus reducing the ductility of the concrete beam.

(4) Small anchor spacing will cause excessive damage to the reinforced concrete in the tension zone during the reinforcement process, too large anchor spacing will cause the carbon plate to peel off and make the carbon plate underutilized.

(5) The width of the CFRP plate should be suitable for the reinforced concrete. If the plate is too narrow, reinforcement effect cannot be ensured. If the plate is too wide, it is easy to peel off. The best condition is that the carbon plate breaks and the rebar withdrawal occurs at the same time.

\section{Acknowledgments}

Fund project: First-class undergraduate major construction project of Yanbian University (Yanbian University Education Development [2020] No. 16)

\section{References}

1. Wang, Wenwei. Study on flexural performance of reinforced concrete beams strengthened by fiber composites. [D] Dalian University of Technology(2003).

2. Ye Leping, Application and development of FRP in engineering structures. Journal of Civil Engineering, 39: 24-36(2006).

3. Shang Shouping, Study on flexural performance of prestressed carbon fiber fabric reinforced concrete flexural members. Journal of Building Structures, 24: 24-30 (2003).

4. Gao Danying, Bending tests and load capacity calculation of carbon fiber fabric reinforced reinforced concrete short beams. Journal of Building Structures, 38: 122-131(2017).

5. Zhao Ming, Experimental study of carbon fiber sheet reinforced reinforced concrete beams in flexure. Structural Engineer: 10:52-58(2002).

6. Wang Suyan, Experimental study on flexural performance of damaged high-strength concrete beams reinforced with carbon fiber cloth. Engineering Seismic and Reinforcement Modification, 28: 93-96(2006).

7. Cheng Ye, Reinforced concrete beam steel plate-FRP composite reinforcement method [D] Dalian University of Technology (2017).

8. Ding Yahong, Overview of FRP reinforcement technology research. Engineering Seismic and Reinforcement Modification: 34: 69-74(2012).

9. Fu Xiao, Experimental study on shear performance of reinforced concrete beams strengthened by FRP hybrid paste technique. [D] Southeast University(2017).
10. Hu Chenghe, Experimental study of FRP composite anchorage technology. Journal of Disaster Prevention and Mitigation Engineering: 30:309-314(2010).

11. Xing, Lili, Research progress on structural performance of externally applied FRP reinforced concrete beams. Concrete: 9: 40-44(2018).

12. Andrea Rizzo, Laura De Lorenzis. (2007) Behavior and Capacity of RC Beams Strengthened in Shear with NSM FRP Reinforcement.,1555 1567. 